\title{
First reports of adverse drug reactions (ADRs) in recent weeks
}

\author{
The following table contains an overview of first published case reports of adverse drug reactions identified in the international \\ literature in recent weeks. Any claim to a 'first report' is verified by a database search of previous literature.
}

\section{Drug and ADR}

Celecoxib: coloured spots in the visual fields in an elderly patient

Citalopram overdose: neuroleptic malignant syndrome (serious)

Clozapine: panic disorder

Digoxin: interaction with concomitant cisapride leading to a decreased serum concentration of digoxin in an elderly patient (serious)

Lithium: interaction with concomitant levofloxacin leading to renal failure and neurological disorders

Methylphenidate: bodyweight loss

Mycophenolate mofetil: hyperbilirubinaemia

Ondansetron/paracetamol/tropisetron: fixed drug eruption in a patient receiving interleukin-2 therapy

(first report with tropisetron)

Paclitaxel/trastuzumab: photosensitivity

Phenytoin: interaction with concomitant capecitabine leading to brain disorders

Reboxetine: interaction with concomitant fluoxetine leading to urinary retention and other anticholinergic effects

Ropivacaine: diplopia

Rosiglitazone/troglitazone: pulmonary and peripheral oedema in the elderly (serious)

Trovafloxacin: leucopenia in an elderly patient

\section{Reference}

Lund BC, Neiman RF. Visual disturbance associated with celecoxib. Pharmacotherapy 2001 Jan; 21: 114-5

Aydin N, Anaç E, Çayköylü, et al. Neuroleptic malignant syndrome due to citalopram overdose. Can J Psychiatry 2000 Dec; 45: 941-2

Bressan RA, Monteiro VBM, Dias CC. Panic disorder associated with clozapine. Am J Psychiatry 2000 Dec; 157: 2056

Kubler PA, Pillans PI, McKay JR. Possible interaction between cisapride and digoxin. Ann Pharmacother 2001 Jan; 35: 127-8

Takahashi H, Higuchi H, Shimizu T. Severe lithium toxicity induced by combined levofloxacin administration. J Clin Psychiatry 2000 Dec; 61: 949-50

Chandramouli JB, Muller BA. Case report of severe weight loss possibly associated with methylphenidate. J Pharmacy Technology 2000 Sep-Oct; 16: 197-201

Chueh S-C, Huang C-Y, Lai M-K. Mycophenolate mofetil-induced hyperbilirubinaemia in renal transplant recipients. Transplantation Proceedings 2000 Nov; 32: 1901-2

Bernand S, Scheidegger EP, Dummer R, et al. Multifocal fixed drug eruption to paracetamol, tropisetron and ondansetron induced by interleukin 2. Dermatology 2000; 210 (2): 148-50

Mermershtain W, Cohen AD, Geffen DB, et al. Cutaneous photosensitivity associated with abberations in the heme biosynthetic pathway induced by taxanes and trastuzumab: a report of 3 cases of metastatic breast cancer [abstract]. Ann Oncol 2000; 11 Suppl. 4: 28

Schaller G, Ebert A, Kuhle A, et al. Drug interaction of capecitabine and phenytoin in the therapy of cerebral and visceral metastatic breast cancer [abstract]. Ann Oncol 2000; 11 Suppl. 4: 139

Benazzi $F$. Urinary retention with reboxetine-fluoxetine combination in a young man. Can J Psychiatry 2000 Dec; 45: 936

Wells AP, Maslin K. Diplopia from peribulbar ropivacaine. Clin Exper Opthamol 2000 Feb; 28 : 32-3

Thomas ML, Lloyd SJ. Pulmonary edema associated with rosiglitazone and troglitazone. Ann Pharmacother 2001 Jan; 35: 123-4

Mitropoulos FA, Angood PB, Rabinovici R. Trovafloxacin-associated leukopenia. Ann Pharmacother 2001 Jan; 35: 41-4

Serious = an event is serious (FDA MedWatch definition) when the patient outcome is death, life-threatening, hospitalisation, disability, congenital anomaly, or requires intervention to prevent permanent impairment or damage. 